This article was downloaded by: [University of Aberdeen]

On: 20 January 2015, At: 03:25

Publisher: Routledge

Informa Ltd Registered in England and Wales Registered Number: 1072954 Registered

office: Mortimer House, 37-41 Mortimer Street, London W1T 3J H, UK

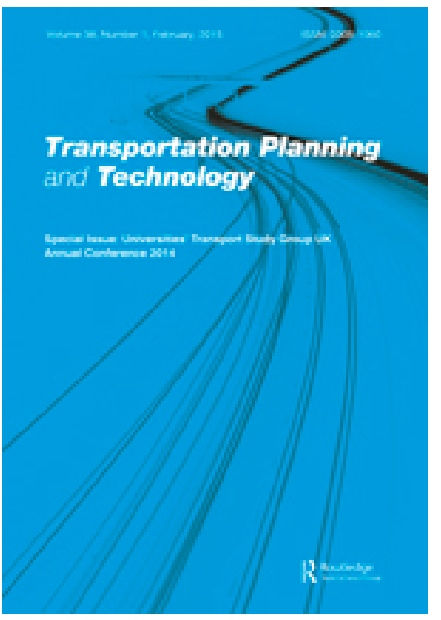

\title{
Transportation Planning and Technology
}

Publication details, including instructions for authors and subscription information:

http:// www. tandfonline.com/ loi/gtpt20

\section{Future prospects for personal security in travel by public transport}

\author{
Mark Beecroft ${ }^{a} \&$ Kate Pangbourne ${ }^{a}$ \\ ${ }^{a}$ Department of Geography and Environment, School of \\ Geosciences, Centre for Transport Research, University of \\ Aberdeen, St Mary's, Aberdeen AB24 3UF, UK \\ Published online: 14 Nov 2014.
}

\section{CrossMark}

Click for updates

To cite this article: Mark Beecroft \& Kate Pangbourne (2015) Future prospects for personal security in travel by public transport, Transportation Planning and Technology, 38:1, 131-148, DOI: 10.1080/03081060.2014.976980

To link to this article: http:// dx.doi.org/ 10.1080/ 03081060.2014.976980

\section{PLEASE SCROLL DOWN FOR ARTICLE}

Taylor \& Francis makes every effort to ensure the accuracy of all the information (the "Content") contained in the publications on our platform. Taylor \& Francis, our agents, and our licensors make no representations or warranties whatsoever as to the accuracy, completeness, or suitability for any purpose of the Content. Versions of published Taylor \& Francis and Routledge Open articles and Taylor \& Francis and Routledge Open Select articles posted to institutional or subject repositories or any other third-party website are without warranty from Taylor \& Francis of any kind, either expressed or implied, including, but not limited to, warranties of merchantability, fitness for a particular purpose, or non-infringement. Any opinions and views expressed in this article are the opinions and views of the authors, and are not the views of or endorsed by Taylor \& Francis. The accuracy of the Content should not be relied upon and should be independently verified with primary sources of information. Taylor \& Francis shall not be liable for any losses, actions, claims, proceedings, demands, costs, expenses, damages, and other liabilities whatsoever or howsoever caused arising directly or indirectly in connection with, in relation to or arising out of the use of the Content. 
This article may be used for research, teaching, and private study purposes. Terms \& Conditions of access and use can be found at http://www.tandfonline.com/page/termsand-conditions

It is essential that you check the license status of any given Open and Open Select article to confirm conditions of access and use. 


\title{
Future prospects for personal security in travel by public transport
}

\author{
Mark Beecroft* and Kate Pangbourne \\ Department of Geography and Environment, School of Geosciences, Centre for Transport \\ Research, University of Aberdeen, St Mary's, Aberdeen AB24 3UF, UK
}

(Received 3 March 2014; accepted 6 October 2014)

\begin{abstract}
This paper reports findings from a project focused on understanding the interaction between transport technologies and user needs and perceptions in supporting personal security in travel by public transport. The research engaged over 60 experts from across the UK transport sector in a combination of interviews, workshops and scenario planning activities to address a set of four application areas in relation to secure travel. These areas were information provision, travel disruption, automated transport services and flexible transport services. Four future scenario narratives (to a 2040 time horizon) were developed for each application area. A final workshop consolidated and reviewed the narrative scenarios and pulled out key themes and priority issues for policy, practice and research for the near term. Consequently a set of policy recommendations, operator and business opportunities, knowledge gaps and research priorities were identified to support and enhance provision for personal security in travel by public transport.
\end{abstract}

Keywords: personal security; public transport; scenarios; technology

\section{Introduction}

Amongst the many advantages that private transport is perceived to hold over public transport (PT) is that it is inherently safer in terms of the individual being subjected to crime. This perception is closely linked to notions of public and private space and the extent to which environments can be controlled (Atkins 1989; Newton 2004). Travelling on PT significantly increases the degree of potential exposure to crime and anti-social behaviour compared to private transport (Stafford 2003). In addition to these general perceptions, major terrorist attacks on PT systems have highlighted their vulnerability to mass threats to the public. Though rare, such events can significantly impact on public perceptions of personal safety and security in travel (Potoglou et al. 2010).

In economic terms, the UK Home Office estimated that in 2006/7 the total costs of actual crime and antisocial behaviour on PT equated to some $£ 822$ million (cited in DfT 2010). This kind of statistic feeds PT's poor image. Negative perceptions and personal experiences of security and safety related issues in travelling by PT can impact upon travel behaviour with consequences for both individuals and society (Lynch and Atkins 1988; Smith and Clarke 2000).

*Corresponding author. Email: m.beecroft@abdn.ac.uk

Present address: Kate Pangbourne, Department of Computing Science, University of Aberdeen, Aberdeen AB24 3UE, UK. 
When negative perceptions deter travel by PT, there can be modal split implications and the knock-on congestion and pollution impacts from the dominance of private motorised transport (Clarke 1996). There can also be significant social exclusion consequences, particularly if private transport options are limited (Smith and Clarke 2000; Social Exclusion Unit 2003). However, successfully increasing patronage levels, particularly at off-peak times, can make a significant positive contribution to perceptions that travel by PT is secure (Smith 2008), creating a virtuous circle.

Technological innovation has an important role to play in supporting greater personal security in travel by PT. This support ranges from underpinning the safe and reliable operation of vehicles, transport systems and services to facilitating individual travel choices, as well as the personal support conferred by mobile phones. Transport-related technologies range from applications specifically designed to address security issues, such as CCTV (though evidence on its effectiveness as a security measure is quite mixed, see Stutzer and Zehnder 2013; Gill and Spriggs 2005), to technologies with more general applications that may incorporate personal security features, or which support confidence in some way, e.g. journey planning services. Private motorists are also being offered powerful technologies, with security and safety features, to enhance their driving experience such as on board software which navigates, provides security, sends an automatic crash response, connects the vehicle to the internet and also incorporates diagnostics (OnStar 2014). However, research undertaken in the ASSURED project (Beecroft, McDonald, and Vöge 2007) has suggested that the 'hearts and minds' of PT users are not yet won over to the benefits of technological solutions that are perceived as mass surveillance and this is likely to be a significant barrier to implementation. This view has been further supported by a UK DfT study into public perceptions of measures to enhance personal security while travelling on PT (DfT 2009).

In order for technological solutions to be robust and to gain public support it is important that they take good account of user needs and perceptions. This project focused on the role of technology and its interaction with user needs and perceptions in supporting personal security in travel on PT. The aim was to develop fundamental understandings relating to this interaction and as a consequence to enable transport technologies to better support personal security (both perceived and actual) in travel by PT. While the research focussed primarily on the UK context there is considerable potential for transferability in the findings.

In this paper we first present our definition of personal security, which is an early empirically-informed outcome from the project which contributes an important conceptual development. We then describe the project methodology. In the remainder of the paper we highlight the personal security implications of the consolidated scenarios, and discuss the participants' perspectives on the policy and research implications that arise in relation to technology and personal security.

\section{Defining personal security}

The term 'personal security' is one that is in general use, and we assumed we knew what it meant. However, it was apparent from the first project workshops that participants tended to focus on different things when discussing personal security, but assumed a common understanding. However we were ultimately surprised not to find any clear definition in the literature. Therefore, we developed an empirically informed definition of personal security at an early stage of the project. 
Personal security has been traditionally viewed as being related to crime and antisocial behaviour (DfT 2009), and security professionals working in the transport domain have a clear focus on addressing the many forms of crime afflicting the transport network (from terrorism right down to petty vandalism and antisocial behaviour). Transport providers are concerned with general security issues, but also have a significant focus on safety (freedom from accident). Both practice communities recognise that addressing negative perceptions about security and safety is important, but tend to do this by presenting objective facts, such as trends in crime or accident statistics. However, participants who were interested in the travel consumer or in addressing social exclusion are more focused on the individual experience of travel and the affective nature of a fear of (potential) crime or accident as a factor that clearly impacts on the confidence to travel at all.

It is apparent to us therefore that the concept of 'personal security' in PT ought to comprise a combination of three aspects, from the perspective of an individual: Security, which is freedom of threat from other people, for example terrorism, violence, theft, or intimidating behaviour; Safety, which is freedom from the impacts of accidents, for example vehicle accidents, safe interchange environments, preventing slips and trips; and Confidence, which is freedom from discomfort, for example, a smooth ride quality, and from fear, for example, from not knowing how to travel, from accident, from threat. This third aspect accounts for personal affective issues. These aspects affect the issue of personal security in PT in different ways, but the perceived importance of each aspect varies by stakeholder perspective. By combining these perspectives that participants implicitly or explicitly attached to personal security in relation to travel, we reach our definition, that personal security is an objective freedom from security and safety risks combined with a subjective freedom from fear and uncertainty.

Figure 1 illustrates our conceptualisation of personal security in relation to travel. This incorporates the three distinct aspects, and illustrates how they overlap and intertwine.

Security accounts for objective issues relating to the impacts of crime and antisocial behaviour.

Safety accounts for objective issues relating to the impacts of accidents, whether occurring to a vehicle, or to an individual (e.g. slipping or tripping while on a vehicle, at an interchange or negotiating the streets between one's front door and the bus).

Confidence accounts for objective issues such as an individual's knowledge and experience of how to undertake a PT journey combined with subjective issues such as capacity and self-belief in relation to undertaking a journey by PT.

Each factor overlaps, for example Security and Safety can compromise one another, if the consequences of crime and antisocial behaviour impact on health and safety, such as when an accident occurs as a result of vandalism.

Security also overlaps with Confidence, as cognitive discomfort arises from transport and public environments affected by crime and antisocial behaviour. This negatively impacts on confidence, not only based on factual knowledge of actual risk, but when combined with individual characteristics and vulnerabilities, a more subjective fear of crime will impact on a traveller's sense of personal security.

Similarly, Safety and Confidence also overlap through the impact of personal concern for safety, i.e. the impact a fear of accidents has on a traveller's confidence to travel (see Backer-Grøndahl et al. 2009; Peel, Westmoreland, and Steinberg 2002). 


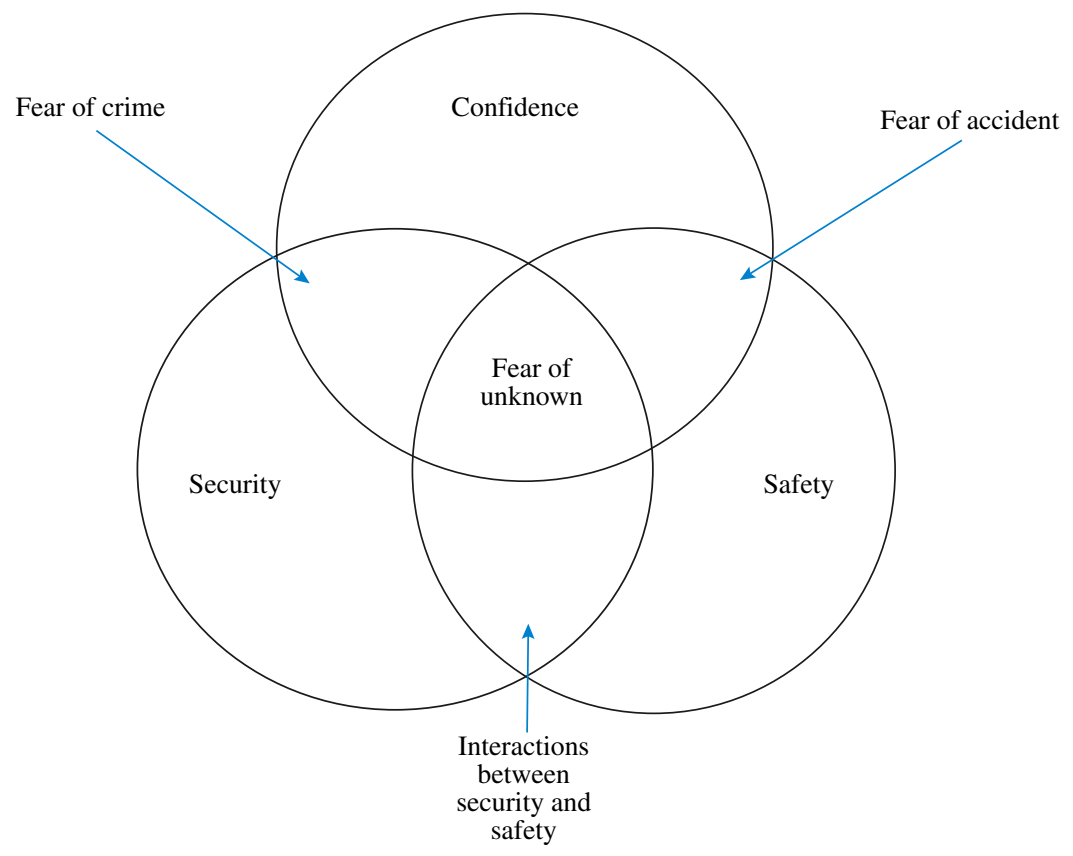

Figure 1. A conceptual framework for personal security.

Source: Beecroft and Pangbourne 2014.

Where Confidence, Security and Safety all overlap in the centre of the diagram, we can say that a subjective and generalised 'fear of the unknown' can exist. We have placed Confidence at the top of the diagram because our focus is on the individual. Many personal or 'hearsay' anecdotes were contributed by all participants to illustrate the more psychological elements of personal security, demonstrating that our participants implicitly recognised that ultimately, only confidence can unlock a sense of Personal Security, even where, objectively, security and safety are optimal. This view is supported by the work of Fyhri and Backer-Grøndahl (2012) and Roche-Cerasi et al. (2013) who have demonstrated links between personality (incorporating confidence) and risk perception in transport use and travel behaviour.

\section{Methodology}

The research combined expert interviews with workshops involving scenario planning activities, across a set of four areas where technology and innovation is being applied, in order to examine the personal security implications. The expert interviews $(n=13)$ were used to triangulate empirical material derived from the workshops $(n=51$ participants across five workshops). The interviews (conducted by telephone) also served to address the issue of geographical coverage within the UK. All workshops were held in central London and almost all interviewees were based outside London. These activities involved the participation of experts from across the UK transport sector including academics, government and transport authorities, transport operators and service providers, consultants, advocacy groups and other third sector bodies as proxies for transport consumers. 
The four application areas (AA) addressed in this research were information provision, travel disruption, automated transport services and flexible transport services (FTS). These areas were selected primarily because of their characteristics as domains where technology and users interact in ways which can influence perception and experience (both positively and negatively) of security and safety in travel. These AA are also experiencing rapid technological innovation which could substantially alter the travel experience and the very nature of PT, and have fairly distinct practice communities.

In the case of information provision, there is a widespread belief that providing information supports confidence (see Kenyon and Lyons 2003; Grotenhuis, Wiegmans, and Rietveld, 2007; Nelson and Mulley 2013). We were particularly interested to discover how far personal security was considered in the provision of information. Travel disruption is an issue which has come rapidly up the political agenda (see Marsden and Docherty 2013; Birtchnell and Büscher 2011), and creates a lot of public disquiet, which can be read as a generalised concern for issues that related to personal security. An aspect that we were interested in was how far personal security was considered in contingency planning for coping with disruption, either by public authorities or by travellers themselves. In relation to the increasing level of automation in transport services, and the promise of a future dominated by driverless vehicles, we were interested in how far a concern for personal security affects public acceptance of automation technologies (see Beecroft, McDonald, and Vöge 2007; Cozens et al. 2003). Finally, in relation to flexible transport services, we were interested in how demand responsive provision for vulnerable groups could expand into more public flexible services through the utilisation of new technologies that safeguard identities and personal details (see DfT and GMPTE 2004).

For each AA four future scenario narratives (to a 2040 time horizon) were developed. As each AA was addressed consecutively the scenario narratives were built iteratively as the project developed, and as a result of the tendency of technology to create convergences between the AAs, the boundaries between them became somewhat blurred as the project progressed, particularly once the consolidated scenarios were produced, as these also benefitted from the insights derived from the expert interviews.

Scenario planning is a forward oriented approach where alternative scenarios are developed for a desired time horizon from the present situation. The methodological approach for scenario planning used in this project sits within the 'Intuitive Logics School' (Bradfield et al. 2005), in that the focus is on the insights and learning that arise from the process. The scenarios are qualitative narratives rather than quantifiable matrices of future conditions that could be retrospectively verified. We adopted scenario planning because of the complexity of the research context, the wide range of potential future developments and the diversity of participant perspectives included in the project.

Within each workshop we dealt with present day first, using SWOT analysis of personal security issues relating to the AA in question, followed by a PESTEL analysis of future drivers for the AA, before moving on to develop the scenarios. As widely used techniques in a business environment, we felt they would be accessible to participants with a minimum of 'training'.

SWOT analysis originated in the 1960 s as a tool to support organisational strategic planning in the business community (Learned et al. 1965). Participants identified currently important strategic factors and characterised them as the Strengths and Weaknesses in the AA, and then identified the Opportunities or Threats in the environment (Dyson 2004). In the context of the workshop approach, this enabled a 
swift move from the categorising of current issues to identifying key drivers that will affect the future development in the AA.

PESTEL analysis provides a framework for considering what key external forces will drive future developments in the AA under consideration. As with SWOT analysis, this technique has its origins in strategic business planning (Fleisher and Bensoussan 2003). The approach requires that key external forces are categorised into Political, Economic, Social, Technological, Environmental and Legislative drivers. The boundaries between these categories can be somewhat fuzzy; nevertheless it provides a useful framework for ordering contributions in a participatory setting, and thinking beyond present day problems.

For the scenario development we used the generic framework developed by Berkhout and Hertin (2002) as it is adaptable to different sectors and areas of application. Figure 2 shows the basic characteristics of the four future worlds, which vary on the $\mathrm{x}$ axis by governance style and on the $y$ axis by social values. We considered these axes (from Berkhout and Hertin 2002) to provide a useful degree of differentiation between the scenario quadrants, especially as transport is a domain where governance and social norms have a particular impact. Scenario narratives were developed by participants in a series of workshops focused on each AA (see Pangbourne and Beecroft 2012a, 2012b, 2013a, 2013b, 2013c).

We followed a common process for each AA, with a set of questions used to guide the development of each scenario narrative as shown in Figure 3. In this figure, each question should be read from left to right, inserting a different word from the central box according to the AA in question. The final workshop was a collaborative synthesis and review activity to scope unintended or undesirable consequences of developments imagined in the four narratives, and pull out key themes and priority issues for policy, practice and

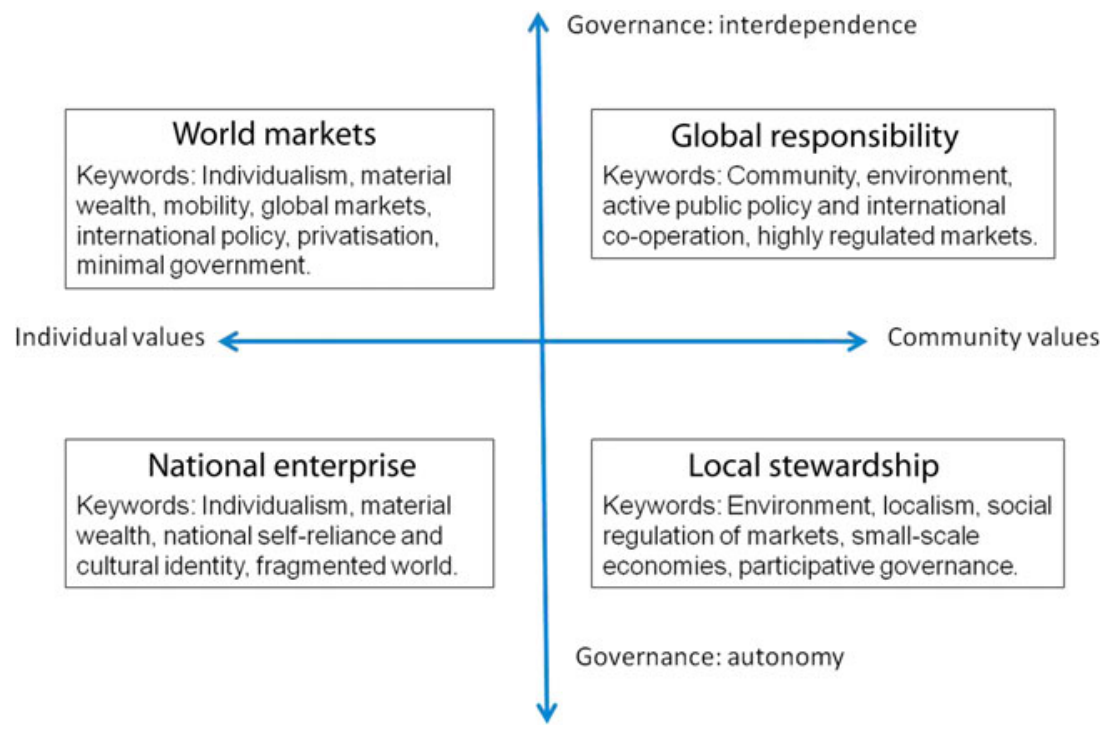

Figure 2. The overarching framework for scenario development.

Source: Developed from Berkhout and Hertin 2002. 


\begin{tabular}{|c|c|c|}
\hline $\begin{array}{l}\text { Under each scenario, what } \\
\text { types of: }\end{array}$ & & $\begin{array}{l}\text { will be most prevalent, and over } \\
\text { what scale will they develop }\end{array}$ \\
\hline $\begin{array}{l}\text { From a passenger perspective - } \\
\text { how comfortable will travellers } \\
\text { be with these types of: }\end{array}$ & & $\begin{array}{l}\text { and what will be their } \\
\text { expectations of support in terms } \\
\text { of information and services? }\end{array}$ \\
\hline $\begin{array}{l}\text { From the operator perspective } \\
\text { - what kind of business models } \\
\text { will operators of: }\end{array}$ & $\begin{array}{l}\text { information } \\
\text { disruption }\end{array}$ & $\begin{array}{l}\text { services develop and how will } \\
\text { passenger confidence and } \\
\text { customer service be prioritised }\end{array}$ \\
\hline $\begin{array}{l}\text { From the local / transport } \\
\text { authority perspective - what } \\
\text { role will authorities have in } \\
\text { governance and resourcing of } \\
\text { services in relation to: }\end{array}$ & $\begin{array}{l}\text { automation } \\
\text { flexibility }\end{array}$ & $\begin{array}{l}\text { (e.g. data protection, } \\
\text { infrastructure provision, social } \\
\text { equity)? }\end{array}$ \\
\hline $\begin{array}{l}\text { What will be the threats to } \\
\text { personal security in relation to: }\end{array}$ & & under this scenario? \\
\hline What will be the solutions to: & & $\begin{array}{l}\text { threats generated under this } \\
\text { scenario? }\end{array}$ \\
\hline
\end{tabular}

Figure 3. Scenario development questions.

research for the near term. Consequently a set of policy recommendations, knowledge gaps and research priorities were identified by participants to enhance provision for personal security in travel by PT.

\section{The consolidated scenarios}

In preparation for the synthesis and review workshop the SWOT and PESTEL analyses were summarised and the scenario narratives developed for each AA were consolidated. This was made possible by the iterative nature of scenario development deployed in the previous workshops. Space precludes presenting consolidated SWOT and PESTEL analyses in this paper. For each Scenario we present a figure which summarises the future envisaged and highlights the key features in relation to each AA (Figures 4 and 5).

\section{Reviewing the consolidated scenarios}

The participants considered that the scenarios were quite plausible in many respects. Indeed, some aspects were identified as already present or developing in particular cities or countries around the world. For example, the Global Responsibility scenario was seen by some as resembling the current Swiss model. The steady modal shift away from cars (as we currently define them) is also seen as plausible, with a suggestion that this trend has already started as evidenced by the ongoing 'peak car debate' (see Goodwin and Van Dender 2013).

However, the high levels of car-based urban mobility in the World Markets scenario was perceived as less likely in dense European city centres, and more comparable to North American and 'new world' city configurations like Sydney (Australia). The envisaged future of a rise in flexible but insecure informal services also has many precursors, particularly in the global south, where these services often predominate and 
- Information is costly, with services quality linked to willingness to pay.

- Data security is a significant issue with high profile breaches commonplace and low levels of trust limit role of social media and open data in society.

- Lower income groups rely on word of mouth for information about informal and unregulated transport services.
- Information provision is highly localised, and travelling between regions becomes harder as a result.

- High levels of active travel spur information services to support safe routing and integration with collective modes.

\begin{tabular}{|ll}
\hline & Travel disruption
\end{tabular}

- Social polarisation renders crime and anti-social behaviour major issues.

- Those who can afford to use bespoke support services to mitigate disruption.

- For the rest of society, risk aversion leads to narrower travel horizons.

- Lack of integration makes cross-boundary travel prone to disruption.

- High levels of active travel make weather-related disruption important.

\section{Automated transport services}

- Automated, surveilled mass transit systems prevail in urban areas.

- Intelligent traffic management through dynamic road-pricing and restricting access is key technology given high levels of car-based mobility.

- A lack of economies of scale slows innovation in automation.

- Integrated ticketing and smartcards fail to develop much beyond the present as the markets are absent.

- The use of biometrics and ID-based access control makes target hardening a

- Wealthy areas develop autonomous vehicle networks, but poorer areas are serious problem for wealthy individuals. more dependent on conventional demand-responsive services.

Flexible transport services

- Increasing role for flexible, dynamic mass PT as costly fixed route PT is reduced in scale and scope outside the primary metropolitan areas.

- Informal sharing and unlicensed and unregulated services abound offering cost savings but with increased security risks.

Figure 4. View of personal security and application areas under World Markets and Local Stewardship. 


\section{Information provision}

- Transport staff, well-trained in soft skills increase passenger confidence.

- Information is provided by multinational corporations who operate data heavy, integrated multimodal transport networks.

- Confidence in travel is supported by use of social media including operators.
- Open data and social media are abandoned.

- Information is carefully controlled by official providers only.

- People depend on mobile 'travel buddies' (apps) to support travel as they mistrust strangers.

\section{Travel disruption}

- The importance of data to transport system operations makes them vulnerable to cyber-attack, but the risks do not dampen public confidence.

- A substantial rise in teleworking reduces dependence on commuting, and modal shift away from cars reduces risks of travel disruption.

- Key national networks and services (including urban mass transit) are well maintained and protected, but peripheral areas suffer endemic disruption.

- Those living outside cities depend on de-regulated and unreliable services or narrow their travel horizons.

\section{Automated transport services}

- Economies of scale and state support for innovation foster the development of automation in transport services.

- Shared-ownership driverless vehicles are widespread, opening up mobility - Cars remain dominant for the wealthy, with limited automation.

- Highly automated high speed rail and intelligent toll roads link the main cities, where mass transit is prevalent. for non-drivers and changing the definition of PT.

\section{Flexible transport services}

- Reduced commuting/increased active travel reduces PT services.

- Low accessibility areas are eliminated, though the 'last mile' is now seen as the 'last 2 plus miles', due to a rise in active travel.
- Automated, dynamic and seamless journey planning, booking and payment through dedicated and integrated brokering services emerge.

- Flexible transport provides feeder services to mass transit/high speed rail.

Figure 5. View of personal security and application areas under Global Responsibility and National Enterprise. 
contribute to extreme traffic management problems (see Finn 2012). The narrower travel horizons foreseen for the less well-off under World Markets and National Enterprise also have current precursors (see Siraut and Gay 2009), participants pointed to UK metropolitan areas such as Merseyside and Greater Manchester which contain distinct pockets where whole communities have extremely localised travel horizons.

National Enterprise was referred to as a fear-led scenario. Populations concentrate in large cities, a trend common to many developing countries in the present day. Participants thought this scenario was particularly plausible, as a result of the environmental and geopolitical impacts of climate change, and that it would involve a lot of down-scaling of expectations and a drive towards self-sufficiency (rather like Cuba after the collapse of the Soviet Union). The less xenophobic but similarly scaled-back Local Stewardship was seen by some participants as also quite depressing, as the retreat from the negatives of globalisation also loses the benefits that global connectivity and awareness have brought. However, while society under Local Stewardship is quite introspective, it has a much stronger sense of personal security, especially in contrast to the National Enterprise and World Market scenarios.

Participants felt that while plausible, all the scenarios were rather pessimistic. Given the lens of personal security, this is perhaps unsurprising. In reality, the kernels of each scenario present in the here and now could develop down myriad possible paths as a result of many unknowable factors and triggers. The scenarios are not mutually exclusive, as their features could be present in different geo-political contexts. Therefore the future for personal security in PT in 2040 is likely to contain elements of all four scenarios plus some completely new developments currently unknown.

\section{Priority issues for policy, practice and research}

The scenarios exercise, though rapid, was comprehensive in that participants fleshed out quite detailed possible future worlds, within which personal security was just one element. In the final workshop we asked participants to 'backcast' from the scenarios to consider present day priorities from a new perspective. While the participants went well beyond enhancing personal security in their recommendations, we focus here only on the insights that can be related directly to personal security.

\subsection{Policy and governance}

\subsubsection{Participant perspectives}

Participants noted a clear need for transport authorities to lead better collaboration, both in terms of inter-organisational information sharing and in developing shared standards, whether for service levels or information and communication technologies. It was recognised that closer collaboration between transport authorities, end users and technology developers was needed to ensure that solutions with real operational and user impact are designed and developed, as a lack of integration between transport modes is often singled out as impacting on passenger confidence in ways that reduces the use of PT.

However, there are considerable regulatory barriers to consistency of approach across different modes, as they operate under different regulatory environments. These differences contribute to perceptible effects on the confidence of transport users, as they 
must 'learn' how to use each individual mode, with their individual access and payment means, and their different norms of public behaviour.

The second recommendation relates strongly to the second AA (enhancing personal security during travel disruption) - the need for resilience planning in transport. The PESTEL analysis and the future scenarios exercise both emphasise that a lack of resilience will result in more frequent system failure, creating disruption that can spread quite widely (in time and space) beyond the initial incident. Disruption is an uncontrolled process which compromises safety, provides opportunities for criminal or antisocial behaviour and undermines confidence.

Furthermore, it was noted that disruptions on one system (or outside the transport system), such as serious fires, already tend to impact very severely on adjacent systems if there is a lack of communication between responsible agencies. While a certain amount of disruption is inevitable, both the geographic spread and the time taken to return to normal operation could be substantially improved, with associated objective and subjective personal security benefits.

Resilience is best assured through investment in the development and maintenance of the network and hubs, particularly by building in appropriate levels of network redundancy to provide 'work arounds' when incidents and failures occur. Vehicle choices, business models and operating practices are relatively ephemeral. Hub points are particularly important in supporting the passenger experience, as they are gathering points in times of disruption. Indeed, one participant noted how during the London riots of August 2011 the well-lit and surveilled Docklands Light Railway stations were seen as safe havens, even though they were unmanned.

Regulation and standards was another area where national government could significantly improve conditions that would support a greater sense of personal security in PT. Measures that could be implemented include:

- Mandating standards in certain key areas, to provide a clear picture to the public of what can be confidently expected when using PT and travel information services: o minimum standards for customer service.

o information sharing standards for real-time data.

- Putting different forms of transport on a more equal regulatory footing (e.g. FTS and PT, taxi and private hire) to support a framework within which services can develop more holistically. This could also involve redefining what constitutes PT, to reflect the innovative new products and business models for achieving A to B mobility that are emerging. A more equal footing supports integration, which enables the public to have greater confidence in switching between modes, particularly were integrated ticketing and booking can be enabled.

A number of other policy recommendations were identified that require supra-national co-ordination in order to be effective. Those relating to personal security include cybersecurity, data security and privacy. If these issues cannot be effectively resolved, the resultant loss of public trust in transport technologies and systems which rely on Big Data (for example) could have impacts on the take up data-driven services such as personalised journey planners, Smartcards and proximity readers. 


\subsubsection{Summary}

There is clear synergy between participant perspectives on policy and governance priorities and wider research evidence. Almost any PT journey involves the passenger traversing a range of travel environments, public and private spaces with different degrees of management and regulation. Negotiating these environments can be stressful and impact upon confidence (see Raje 2007; Smith and Cornish 2006), which has been identified as a critical determinant in an individual's sense of personal security in our conceptual model.

At the operational level, the fragmentation of responsibility across the space of travel environments is a clear barrier to consistency in the provision of services to travellers and so both better collaboration and clear standards are key ways to mitigate this problem. Resilience planning is intrinsically linked to collaboration and the participants' focus on this issue is consistent with research evidence which identifies resilience planning as integral to the development of safe and secure transport systems (see Sircar et al. 2013; Reggiani 2013).

The participants' discussion on the regulation of FTS reinforces one of the key messages to emerge from the scenario planning exercises. All of the futures envisaged in the scenarios saw a different picture of PT from that of today. They largely agree that the blurring of boundaries between public and private transport will continue apace. There will need to be services available to meet demand ranging from conventional fixed route services to highly dynamic services with a plethora of alternative service models in between. A more flexible approach to regulation will be a key enabler of this transition.

\subsection{Operator and business opportunities}

\subsubsection{Participant perspectives}

Participants believed that the most significant business opportunity for transport operators from transport and transport-related technology is to use Big Data not only to improve service delivery, but to understand more about their customers - what they want, and what they need.

Gathering better intelligence on the travel behaviour and requirements of customers could lead to the greater personalisation of information leading to more tailored services (as envisaged in several scenarios). On the positive side, personalisation boosts confidence as information provided is tailored to the individual customer's needs. On the negative side personalisation is predicated on the willing 'giving up' of a great deal of personal information, including location, which has security and privacy implications. Participants felt that resolving this conundrum would be a major challenge and the tradeoffs involved would depend on the social and governmental environments (hence the different perspectives on these 'driving forces' under the four future scenarios). Key considerations would be likely to include data management protocols for information service providers and the alignment of industry standards and regulations that are flexible enough to allow development and innovation.

Opportunities were also identified to use the dynamism possible with technology to spread peak demand on transport networks through differential pricing. Spreading loadings, particularly reducing over-crowding, but also increasing off-peak custom, were identified as providing security benefits. Participants were of the view that surveillance is easier with less crowding with current technology; and passengers are more comfortable and less stressed in less crowded conditions. Conversely, in off-peak 
periods (particularly at night) passengers are more reassured if there are more people travelling. For operators, this would also enable vehicles and other resources to be used more efficiently, a direct business benefit that is also indirectly beneficial to customers.

\subsubsection{Summary}

Personalisation of information has been a theme throughout the project, and has both positive and negative connotations for personal security. However, the question mark over the privacy of personal data raised by the participants is a societal issue that goes well beyond the transport sector and is a global issue (see policy recommendations above); all sectors that perceive business and customer benefits from utilising personal data will need to participate in the international debate.

The potential to utilise technology to spread temporal demand for transport networks and services seems to offer significant potential benefits for personal security in travel. The participants' perspectives on the security issues associated with peak and off-peak travel are well supported in the research literature on spatio-temporal patterns of crime (Felson 2006; Ceccato and Uittenbogaard 2014; Uittenbogaard and Ceccato 2012; Smith and Cornish 2006).

\subsection{Knowledge gaps}

\subsubsection{Participant perspectives}

Some 28 different knowledge gaps were identified by participants. Fully half of the comments related to the general ignorance of PT operators regarding their customers. It was noted that they know a small amount about their customers and that they know very little about non-customers (largely car drivers).

Understanding how issues of personal status and values are conveyed by the travel choices we make and the circumstances in which we adapt or adjust choices was identified as a critical means to address knowledge deficiencies in this area. Examining research into driver segmentation was cited as a good starting point (Anable 2005).

Participants were hopeful that it may be possible to segment people by their attitudes to personal security and how it affects travel behaviour. In relation to personal security concerns as a barrier to modal shift, participants agreed that car drivers feel safer in cars than on PT, even though this may be a biased and incorrect perception. It is not known how significant a barrier personal security concerns are to PT use, and it is not known how they interact with other issues, or how different combinations of changes to PT offerings would switch car users to PT.

Participants felt that little was known regarding user perceptions of personal security; therefore it was hard for operators and authorities to know the true impact of security and safety measures, or confidence boosting measures on customer perceptions and ridership. Not enough is known about the gap between individual perceptions of personal security concerns and actual risks, and how that affects PT patronage or travel horizons.

In an effort to try and address some of the deficiencies in terms of knowledge of the customer, it was suggested that a large-scale, continuous exercise could be undertaken in combination with smart ticketing to constantly capture data and process it to reveal travel patterns of individuals. This raises wider issues of relevance to personal security, in relation to individuals' concerns about data and personal privacy as noted above. Investigating trade-offs between data privacy and the benefits to individuals (in terms of convenience, service quality or personal security) of releasing data was seen as being an 
area that needs a lot more work. Participants perceived that little appears to be known about either attitudes or practices towards data privacy in the transport domain nor how this relates to personal security.

Participants identified automation as an area where there was a great deal of uncertainty and therefore significant knowledge gaps. This was seen as a highly dynamic area with potential to significantly impact on travel behaviour. In general terms costbenefit analysis of the increasing automation in transport, and the implications for operations, was called for, as was work to determine the 'value' to the customer of personal security provisions. Existing work by Potoglou et al. (2010) on choice experiments in relation to the valuation of security measures was cited as being relevant.

\subsubsection{Summary}

The knowledge gaps perceived by the participants could be argued to be a mixture of genuine knowledge gaps (where there is a lack of research into the topic area, perhaps due to the recent nature of the issue or its perceived complexity/difficulty) and perceived gaps (where existing research evidence has not transferred beyond academia to the wider transport industry). Regarding knowledge of user perceptions of personal security and their travel choices, there is a limited, but developing literature (see Cozens et al. 2003; Smith and Cornish 2006; Delbosc and Currie 2012). Similarly, evidence is beginning to be consolidated regarding attitudes to privacy and data use in the transport domain (see Cruickshanks and Waterson 2012; Cottrill and Thakuriah 2014).

\subsection{Research priorities}

Having identified opportunities and knowledge gaps, participants were asked to prioritise research areas and questions. A brainstorm of research priorities was conducted in which participants were asked to put down any research area or question that they felt was important. A facilitated discussion condensed an initial list from 19 separate items to 8 . Participants were then asked to vote on their top three priorities from the condensed list. The method was to select three priorities, but not rank them. Based on the number of votes cast, the leading research priorities (based on number of votes) were:

(1) Consolidating and disseminating results of existing research for a wider audience.

(2) Understanding the customer and non-customer and their attitudes to personal security.

(3) Interdisciplinary research combining quantitative Big Data with qualitative Rich Data.

That there is a consensus of participants' views regarding consolidating and disseminating existing research for a wider audience is significant. This suggests that most people associated with the industry, either as operators, authorities or academics know that there has been a huge amount of relevant research. However, what seems clear is that the results of this research are not reaching operators and authorities in any digestible way.

The consensus around understanding PT customers and non-customers in general, as well as their attitudes to personal security in particular, is also very strong. Clearly, not nearly enough is known by operators and authorities about what people want, or about how attitudes to personal security are formed or changing in relation to IT developments. Participants called for more joint industry/academic research in this field. 
Interdisciplinary research utilising the possibilities of big data and combining that with qualitative research was also seen as a high priority amongst participants, and clearly is an approach that is compatible with both items 1 and 2 . These research priorities can be taken forward by academics, but this will only be effective if there is close collaboration with industry.

\section{Conclusions}

This research project engaged over 60 experts from across the transport sector to speculate regarding future scenarios for personal security in travel by PT in the UK. This activity has created distinct, divergent depictions of the future containing both positive and negative outcomes with social and economic implications going far beyond the issue of personal security. Following this work, a final workshop was held to reflect upon these scenarios and to link this future thinking to tangible near-term decisions that should be made to support desirable outcomes and mitigate against more dystopian personal security outcomes identified in these scenarios.

In terms of governance, policy recommendations were seen as a higher order framing that would have indirect benefits for personal security. More and better collaboration between authorities, operators and users was the identified watchword with clear links from this to other key priorities such as resilience planning and data sharing. For national government, appropriate regulation and standard setting require priority attention. It is significant, however, that some major issues, particularly around data and cyber security, will require supra-national co-ordination.

The degree to which operators and transport-related service providers can adapt to future scenarios and the trends which underpin them will be contingent upon identifying and grasping emerging business opportunities. The ability to know and understand customer travel requirements and provide personalised information and services is likely to be the key to yielding competitive advantages in this field, while also having the potential to deliver positive personal security benefits for passengers.

However, when considering knowledge gaps and research priorities it is clear that some profound problems remain. Simply knowing and understanding the customer is a major challenge for the whole transport industry, government and academia. The exponential surge in the ability to gather data (particularly through mobile platforms) to support greater understanding offers great potential in this area. However success will be dependent upon having the skills and capacity to analyse and utilise this data effectively, and the ethics of the data's very existence is a matter of concern that intertwines with personal security for some people.

Our limited understanding of user and (critically) non-user perceptions of PT (both in general and specific to personal security), and the relationship between perception and actual practice remain crucial issues. Going forward, addressing these issues is fundamental to enhance secure and confident travel by PT.

\section{Funding}

This work was supported by the Engineering and Physical Sciences Research Council [grant number EP/I037032/1]. No other funding support from any other bodies was provided. 


\section{References}

Anable, J. 2005. “'Complacent Car Addicts' or 'Aspiring Environmentalists'? Identifying Travel Behaviour Segments Using Attitude Theory." Transport Policy 12 (1): 65-78. doi:10.1016/j. tranpol.2004.11.004.

Atkins, S. 1989. Critical Paths: Designing for Secure Travel. London: Design Council.

Backer-Grøndahl, A., A. Fyhri, P. Ulleberg, and A. H. Amundsen. 2009. "Accidents and Unpleasant Incidents: Worry in Transport and Prediction of Travel Behavior." Risk Analysis 29 (9): 1217-1226. doi:10.1111/j.1539-6924.2009.01266.x.

Beecroft, M., M. McDonald, and T. Vöge. 2007. "Achieving Personal Security in Future Domestic Travel - Technology and User Needs." Institution of Engineering \& Technology, Intelligent Transport Systems 1 (2): 69-74. doi:10.1049/iet-its:20060064.

Beecroft, M., and K. Pangbourne. 2014. "Personal Security in Travel by Public Transport: The Role of Traveller Information and Associated Technologies." Institution of Engineering \& Technology, Intelligent Transport Systems. doi:10.1049/iet-its.2013.0166.

Berkhout, F., and J. Hertin. 2002. "Foresight Futures Scenarios: Developing and Applying a Participative Strategic Planning Tool." Greener Management International 37: 37-52. doi:10.9774/GLEAF.3062.2002.sp.00005.

Birtchnell, T., and M. Büscher. 2011. "Stranded: An Eruption of Disruption." Mobilities 6 (1): 1-9. doi:10.1080/17450101.2011.532648.

Bradfield, R., G. Wright, G. Burt, G. Cairns, and K. Van Der Heijden. 2005. "The Origins and Evolution of Scenario Techniques in Long Range Business Planning." Futures 37 (8): 795-812. doi:10.1016/j.futures.2005.01.003.

Ceccato, V., and A. C. Uittenbogaard. 2014. "Space-Time Dynamics of Crime in Transport Nodes." Annals of the Association of American Geographers 104 (1): 131-150. doi:10.1080/ 00045608.2013.846150.

Clarke, R. 1996. "Editor's Introduction: Crime and the Economics of Mass Transit." In Preventing Mass Transit Crime. Crime Prevention Studies, Volume 6, edited by R. Clarke, 1-4. New York: Criminal Justice Press.

Cottrill, C. D., and Thakuriah, V. 2014. "Privacy in Context: An Evaluation of Policy-based Approaches to Location Privacy Protection." International Journal of Law and Information Technology 22 (2): 178-207. doi:10.1093/ijlit/eat014.

Cozens, P., R. Neale, J. Whitaker, and D. Hillier. 2003. "Managing Crime and the Fear of Crime at Railway Stations-a Case Study in South Wales (UK)." International Journal of Transport Management 1: 121-132. doi:10.1016/j.ijtm.2003.10.001.

Cruickshanks, S., and B. Waterson. 2012. "Will Privacy Concerns Associated with Future Transport Systems Restrict the Public's Freedom of Movement?" Procedia - Social and Behavioral Sciences 48: 941-950. doi:10.1016/j.sbspro.2012.06.1071.

Delbosc, A., and G. Currie. 2012. "Modelling the Causes and Impacts of Personal Safety Perceptions on Public Transport Ridership." Transport Policy 24: 302-309. doi:10.1016/j. tranpol.2012.09.009.

DfT (Department for Transport). 2009. Passengers' Perceptions of Personal Security on Public Transport - Qualitative Research Report. Accessed February 11, 14. http://www.dft.gov.uk/pgr/ crime/personalsecurity/passengerperceptionssecurity/pdf/passengersperceptionssec.pdf.

DfT (Department for Transport). 2010. Estimated Costs to Society of Crime on Public Transport in England 2006/07. Final Report on Findings. Accessed February 11, 14. http://webarchive. nationalarchives.gov.uk/20111005175955/http://www.dft.gov.uk/publications/estimated-societycosts-public-transport-crime-england-2006-07.

DfT (Department for Transport) and GMPTE (Greater Manchester Passenger Transport Executive). (2004). INTERMODE: Innovations in Demand Responsive Transport. Final Report. Accessed November 12, 2010. http://design.open.ac.uk/potter/documents/INTERMODE.pdf.

Dyson, R. G. 2004. "Strategic Development and SWOT Analysis at the University of Warwick." European Journal of Operational Research 152 (3): 631-640. doi:10.1016/S0377-2217(03) 00062-6.

Felson, M. 2006. Crime and Everyday Life: Insights and Implications for Society. London: Sage.

Finn, B. 2012. "Towards Large-scale Flexible Transport Services: A Practical Perspective from the Domain of Paratransit." Research in Transportation Business \& Management 3: 39-49. doi:10.1016/j.rtbm.2012.06.010. 
Fleisher, C., and B. Bensoussan. 2003. Strategic and Competitive Analysis: Methods and Techniques for Analyzing Business Competition. Upper Saddle River, NJ: Prentice Hall.

Fyhri, A., and A. Backer-Grøndahl. 2012. "Personality and Risk Perception in Transport." Accident Analysis and Prevention 49: 470-475. doi:10.1016/j.aap.2012.03.017.

Gill, M., and A. Spriggs. 2005. Assessing the impact of CCTV. London: Home Office Research, Development and Statistics Directorate.

Goodwin, P., and K. Van Dender. 2013. "“Peak Car' Themes and Issue." Transport Reviews 33 (3): 243-254. doi:10.1080/01441647.2013.804133.

Grotenhuis, J.-W., B. W. Wiegmans, and P. Rietveld. (2007). "The Desired Quality of Integrated Multimodal Travel Information in Public Transport: Customer Needs for Time and Effort Savings." Transport Policy 14 (1): 27-38. doi:10.1016/j.tranpol.2006.07.001.

Kenyon, S., and G. Lyons. 2003. "The Value of Integrated Multimodal Traveller Information and Its Potential Contribution to Modal Change." Transportation Research Part F: Traffic Psychology and Behaviour 6 (1): 1-21. doi:10.1016/S1369-8478(02)00035-9.

Learned, E. P., C. R. Christensen, K. E. Andrews, and W. D. Guth. 1965. Business Policy: Text and Cases. Homewood, IL: Irwin.

Lynch, G., and S. Atkins. 1988. "The Influence of Personal Security Fears on Women's Travel Patterns." Transportation 15 (3): 257-277. doi:10.1007/BF00837584.

Marsden, G., and I. Docherty. 2013. "Insights on Disruptions as Opportunities for Transport Policy Change." Transportation Research Part A: Policy and Practice 51: 46-55. doi:10.1016/j. tra.2013.03.004.

Nelson, J., and C. Mulley. 2013. "The Impact of the Application of New Technology on Public Transport Service Provision and the Passenger Experience: A Focus on Implementation in Australia." Research in Transportation Economics 39: 300-308. doi:10.1016/j.retrec.2012. 06.028 .

Newton, A. 2004. "Crime on Public Transport: 'Static' and 'Non-Static' (Moving) Crime Events." Western Criminology Review 5 (3): 25-42. Accessed February 11, 14. http://wcr.sonoma.edu/ v5n3/newton.htm.

OnStar website. 2014. "OnStar Homepage." Accessed July 1. https://www.onstar.com/us/en/4glte/.

Pangbourne, K., and M. Beecroft. 2012a. Coping with Uncertainty and Disruption in Travel by Public Transport. Workpackage 2 Report of Research Project "Enhancing Transport Technologies to Support Personal Security in Travel by Public Transport: Scenarios for 2040". Aberdeen: Centre for Transport Research, University of Aberdeen.

Pangbourne, K., and M. Beecroft. 2012b. Enhancing Transport Technologies to Support Personal Security in Travel by Public Transport: Scenarios for 2040. Workpackage 1 Report of Research Project "Enhancing Transport Technologies to Support Personal Security in Travel by Public Transport: Scenarios for 2040". Aberdeen: Centre for Transport Research, University of Aberdeen.

Pangbourne, K., and M. Beecroft. 2013a. Enhancing Transport Technologies to Support Personal Security in Travel by Public Transport: Scenarios for 2040 Workshop 5 Report: Synthesis and Review. Aberdeen: Centre for Transport Research, University of Aberdeen.

Pangbourne, K., and M. Beecroft. 2013b. Personal Security Barriers to Implementing Automation in Public Transport. Workpackage 3 Report of Research Project "Enhancing Transport Technologies to Support Personal Security in Travel by Public Transport: Scenarios for 2040". Aberdeen: Centre for Transport Research, University of Aberdeen.

Pangbourne, K., and M. Beecroft. 2013c. Personal Security and Flexible Transport Services: Workshop 4 Report of Research Project "Enhancing Transport Technologies to Support Personal Security in Travel by Public Transport: Scenarios for 2040". Aberdeen: Centre for Transport Research, University of Aberdeen.

Peel, N., J. Westmoreland, and M. Steinberg. 2002. "Transport Safety for Older People: A Study of Their Experiences, Perceptions and Management Needs." Injury control and safety promotion 9 (1): 19-24. doi:10.1076/icsp.9.1.19.3327.

Potoglou, D., N. Robinson, C. W. Kim, P. Burge, and R. Warnes. 2010. "Quantifying Individuals' Trade-offs between Privacy, Liberty and Security: The Case of Rail Travel in UK." Transportation Research A - Policy and Practice 44 (3): 169-181. doi:10.1016/j.tra.2009.12.006.

Raje, F. 2007. Negotiating the Transport System. Aldershot: Ashgate. 
Reggiani, A. 2013. "Network Resilience for Transport Security: Some Methodological Considerations". Transport Policy 28: 63-68. doi:10.1016/j.tranpol.2012.09.007.

Roche-Cerasi, I., T. Rundmo, J. F. Sigurdson, and D. Moe. 2013. "Transport Mode Preferences, Risk Perception and Worry in a Norwegian Urban Population." Accident Analysis \& Prevention 50: 698-704. doi:10.1016/j.aap.2012.06.020.

Siraut, J., and N. Gay. 2009. "Expanding Travel Horizons: Overcoming Barriers to Travel for Socially Excluded Groups.” Local Economy 24 (8): 694-704. doi:10.1080/02690940903367967.

Sircar, I., D. Sage, C. Goodier, P. Fussey, and A. Dainty. 2013. "Constructing Resilient Futures: Integrating UK Multi-stakeholder Transport and Energy Resilience for 2050." Futures 49: 49-63. doi:10.1016/j.futures.2013.04.003.

Smith, M. J. 2008. "Addressing the Security Needs of Women Passengers on Public Transport." Security Journal 21 (1): 117-133. doi:10.1057/palgrave.sj.8350071.

Smith, M. J., and R. V. Clarke. 2000. "Crime and Public Transport." Crime and Justice, 27, 169-233. Accessed February 11, 14. http://www.jstor.org/discover/10.2307/1147664?uid=37380 32\&uid $=2129$ \&uid $=2 \&$ uid $=70$ \&uid $=4 \&$ sid $=21103378947661$.

Smith, M. J., and D. B. Cornish. 2006. Secure and Tranquil Travel-Preventing Crime and Disorder on Public Transport. London: UCL Jill Dando Institute of Crime Science, University of London.

Social Exclusion Unit. 2003. Making the Connections: Final Report on Transport and Social Exclusion. London: Her Majesty's Stationary Office.

Stafford, J. 2003. "Safer Travel by Design: Reducing Crime on Transport." Proceedings of the Institution of Civil Engineers Municipal Engineer 156 (2): 87-88. doi:10.1680/muen.2003.156. 2.87 .

Stutzer, A., and M. Zehnder. 2013. "Is Camera Surveillance an Effective Measure of Counterterrorism?" Defence and Peace Economics 24 (1): 1-14. doi:10.1080/10242694.2011.650481.

Uittenbogaard, A. C., and Ceccato, V. 2012. "Space-time Clusters of Crime in Stockholm, Sweden." Review of European Studies 4: 148-56. Accessed July 1, 14. http://search.proquest. com/docview/1286687096? accountid=8155. 